\title{
Inhibitory effects of resveratrol on the adhesion, migration and invasion of human bladder cancer cells
}

\author{
YU BAI $^{*}{ }^{*}$, HONG YANG $^{1 *}$, GUOYING ZHANG $^{1}$, LIBING HU $^{1}$, YONGHONG LEI ${ }^{1}$,

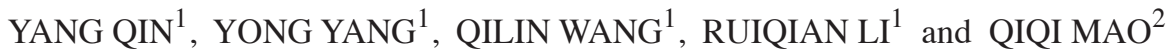 \\ ${ }^{1}$ Department of Urology, The Third Affiliated Hospital of Kunming Medical University, Tumor Hospital of Yunnan Province, \\ Kunming, Yunnan 650118; ${ }^{2}$ Department of Urology, The First Affiliated Hospital, School of Medicine, \\ Zhejiang University, Hangzhou, Zhejiang 310003, P.R. China
}

Received November 9, 2015; Accepted November 4, 2016

DOI: $10.3892 / \mathrm{mmr} .2016 .6051$

\begin{abstract}
Resveratrol is a polyphenolic compound, which has been revealed to induce apoptosis in numerous human cancer cells; however, the effects of resveratrol on the migration and invasion of human bladder cancer cells have not been reported. The present study aimed to evaluate the anti-metastatic potential of resveratrol against bladder cancer and its mechanism of action. The results indicated that resveratrol inhibits the adhesion, migration and invasion of bladder cancer cells in a dose-dependent manner. Resveratrol was shown to significantly inhibit the expression and secretion of matrix metalloproteinase (MMP)-2 and MMP-9 in bladder cancer cells. Furthermore, resveratrol suppressed the phosphorylation of c-Jun N-terminal kinase and extracellular signal-regulated protein kinase. In conclusion, the present study is the first, to the best of our knowledge, to demonstrate that resveratrol may be considered a novel anticancer agent for the treatment of bladder cancer via the inhibition of migration and invasion.
\end{abstract}

\section{Introduction}

Bladder cancer is the fourth most common type of cancer, and was the cause of $>11,510$ cases of cancer-associated mortality among men in the USA in 2014 (1). The majority of bladder cancer cases are noninvasive, low-grade transitional cell carcinoma (TCC); however, $\leq 30 \%$ of all diagnosed tumors are classified as invasive TCC, which is associated with high mortality (2). Notably, among all of the various types of cancer, bladder cancer exhibits a significantly high incidence

Correspondence to: Dr Qiqi Mao, Department of Urology, The First Affiliated Hospital, School of Medicine, Zhejiang University, 79 Qingchun Road, Hangzhou, Zhejiang 310003, P.R. China

E-mail:mqqzju@126.com

${ }^{*}$ Contributed equally

Key words: resveratrol, bladder cancer, migration, invasion, matrix metalloproteinase of recurrence post-treatment, and therefore is recognized as the most expensive cancer to treat. Due to the high prevalence and frequent tumor recurrence associated with bladder cancer, the exploration of preventative strategies is required.

Previous epidemiological and scientific studies have indicated that plant-derived phytochemicals may be beneficial in the prevention and treatment of cancer (3-5). Resveratrol is a polyphenolic compound, which is present in grapes (red wine), knotweed, peanuts, mulberries and other plants. Numerous studies have suggested that resveratrol may prevent the progression of various pathologies, including vascular diseases, ischemic injuries, cancer and neurodegenerative disorders (6-8). Furthermore, it has previously been confirmed that resveratrol exerts antiproliferative and/or apoptotic effects on leukemia, prostate, breast and colon cancers cells in vitro (9-12). Previous studies regarding the anticancer effects of resveratrol have focused on its anti-invasive and anti-metastatic activities (13-15). However, to the best of our knowledge, there is currently no evidence as to whether resveratrol may inhibit the migration and invasion of human bladder cancer cells.

Metastasis is one of the hallmarks of advanced cancer progression, and cancer cell migration and invasion are crucial events in bladder cancer metastasis. Matrix metalloproteinases (MMPs), including MMP-2 and MMP-9, degrade the basement membrane and extracellular matrix (ECM), and are therefore considered crucial proteolytic proteinases that facilitate the invasion of malignant cells (16). Upregulated MMP expression and activity has been reported to serve a key role in several types of human cancer with invasive and metastatic capabilities (17).

The present study aimed to evaluate whether resveratrol alters metastatic tumor cell progression in vitro and its underlying mechanism. The results indicated that resveratrol was able to suppress adhesion, migration and invasion of T24 cells via the c-Jun N-terminal kinase $1 / 2(J N K 1 / 2)$ and extracellular signal-regulated protein kinase 1/2 (ERK1/2) signaling pathways, and the modulation of MMP-2 and MMP-9.

\section{Materials and methods}

Reagents. Resveratrol (purity, >99\%) was purchased from Sigma-Aldrich; Merck Millipore (Darmstadt, Germany). The 
primary antibodies mouse anti-MMP-2 (catalog no. sc-13595), mouse anti-MMP-9 (catalog no. sc-21733), mouse anti-phosphorylated (p)-ERK1/2 (catalog no. sc-81492), mouse anti-ERK1/2 (catalog no. sc-135900), mouse anti-p-JNK1/2 (catalog no. sc-293137), mouse anti-JNK1/2 (catalog no. sc-7345) and mouse anti- $\beta$-actin (catalog no. sc-47778), and a horseradish peroxidase-conjugated goat anti-mouse secondary antibody (catalog no. sc-2031), were purchased from Santa Cruz Biotechnology, Inc. (Dallas, TX, USA). The bicinchoninic acid protein assay kit was purchased from Pierce; Thermo Fisher Scientific, Inc. (Waltham, MA, USA).

Cell culture. The T24 human bladder cancer cell line was obtained from the Shanghai Institute of Cell Biology, Chinese Academy of Sciences (Shanghai, China). The cells were cultured in RPMI-1640 medium (HyClone; GE Healthcare, Logan, UT, USA) supplemented with $10 \%$ heat-inactivated fetal bovine serum (FBS; SAFC Biosciences Inc., Lenexa, KS, USA), $100 \mathrm{U} / \mathrm{ml}$ penicillin and $100 \mathrm{mg} / 1$ streptomycin. Cultures were maintained in a humidified atmosphere containing $5 \%$ $\mathrm{CO}_{2}$ at $37^{\circ} \mathrm{C}$.

Cell adhesion assay. A 96-well plate was coated with $10 \mu \mathrm{g} / \mathrm{ml}$ fibronectin (Corning Life Sciences, Corning, CA, USA) and incubated for $60 \mathrm{~min}$, after which the plate was blocked with $1 \%$ bovine serum albumin (Sigma-Aldrich; Merck Millipore) at $37^{\circ} \mathrm{C}$ for $30 \mathrm{~min}$. Subsequently, cells $\left(5 \times 10^{5}\right.$ cells $\left./ \mathrm{ml} ; 200 \mu \mathrm{l}\right)$ were added to each well and were incubated with resveratrol (0-100 $\mu \mathrm{M})$ or vehicle $(0.1 \%$ dimethyl sulfoxide), for $90 \mathrm{~min}$ at $37^{\circ} \mathrm{C}$, after which the plate was gently washed three times with PBS to remove unattached cells. A total of $20 \mu \mathrm{l}$ MTT $(5 \mathrm{mg} / \mathrm{ml})$ was then added to each well, and the plate was incubated for $4 \mathrm{~h}$ at $37^{\circ} \mathrm{C}$. Subsequently, the liquid was removed and dimethyl sulfoxide was added to dissolve the solid residue. Following agitation for $10 \mathrm{~min}$, absorbance was measured at a wavelength of $490 \mu \mathrm{m}$ using an ELISA plate reader. The adhesion of cells treated with the vehicle was established as $100 \%$.

Cell migration assay. T24 cells ( $1 \times 10^{5}$ cells/well) were allowed to form a confluent monolayer in 6-well plates, after which cells were wounded using a $200-\mu 1$ pipette tip. Following wound generation, all cells in the plates were treated with resveratrol at final concentrations of $0,10,25$ and $50 \mu \mathrm{M}$. Images were captured under a phase contrast microscope at x100 magnification (Olympus IX70; Olympus Corporation, Tokyo, Japan) immediately, or 6, 12 or $24 \mathrm{~h}$ after wound generation. Image-Pro Plus 5.0 software (Media Cybernetics, Inc., Rockville, MD, USA) was used to quantify the cell-free wound area over the period of the experiment. Cell migration was calculated as the percentage of the remaining cell-free area compared with the area of the initial wound.

Cell invasion assay. A 24-well Boyden chamber with a polycarbonate membrane (pore size, $8 \mu \mathrm{m}$; Corning Inc., Corning, NY, USA) was used to analyze cell motility. The membrane was pre-coated with Matrigel to form a matrix barrier. T24 cells were plated at $5 \times 10^{6}$ cells $/ \mathrm{ml}$ in the upper compartment and were cultured in medium containing resveratrol $(0-50 \mu \mathrm{M})$ for $24 \mathrm{~h}$. The bottom chambers were filled with $500 \mu \mathrm{l}$ medium supplemented with $20 \%$ FBS as a chemoattractant.
Cells were incubated at $37^{\circ} \mathrm{C}$ for $24 \mathrm{~h}$ and those that did not migrate through the pores were removed by scraping the upper surface of the membrane with a cotton swab. Cells that had migrated to the lower surface of the membrane were fixed in $100 \%$ methanol for $5 \mathrm{~min}$ and were stained with $0.1 \%$ crystal violet for $2 \mathrm{~min}$. The cells that invaded through the insert were counted in five randomly selected microscopic fields (magnification, x400; Olympus IX70; Olympus Corporation, Tokyo, Japan) per filter.

Western blot analysis. Cells were harvested $24 \mathrm{~h}$ after treatment with resveratrol $(0-50 \mu \mathrm{M})$. The harvested cells were washed and lysed with lysis buffer [10 mmol/1 Tris- $\mathrm{HCl}, 0.25 \mathrm{~mol} / 1$ sucrose, $5 \mathrm{mmol} / 1 \mathrm{EDTA}, 50 \mathrm{mmol} / \mathrm{l} \mathrm{NaCl}, 30 \mathrm{mmol} / \mathrm{l}$ sodium pyrophosphate, $50 \mathrm{mmol} / 1 \mathrm{NaF}, 1 \mathrm{mmol} / 1 \mathrm{Na}_{3} \mathrm{VO}_{4}, 1 \mathrm{mmol} / 1$ PMSF, and $2 \%$ protease inhibitor cocktail ( $\mathrm{pH} 7.5$ )]. Protein concentration in the resulting lysate was determined using the bicinchoninic acid protein assay. Appropriate quantities of protein (20-30 $\mu \mathrm{g})$ were separated by electrophoresis in 10-12\% Tris-glycine polyacrylamide gels, and were transferred to nitrocellulose membranes. The membranes were then blocked with $5 \%$ nonfat milk in TBS for $1 \mathrm{~h}$ at $37^{\circ} \mathrm{C}$, and were incubated overnight at $4^{\circ} \mathrm{C}$ with the appropriate primary antibodies at dilutions according to the manufacturer's protocols (1:200). Subsequently, the membranes were washed with TBS containing Tween-20 (10 mM Tris- $\mathrm{Cl}$ at $\mathrm{pH}$ 7.4, $150 \mathrm{mM}$ $\mathrm{NaCl}, 0.1 \%$ Tween-20) and incubated with the corresponding horseradish peroxidase-conjugated secondary antibody at a 1:2,000 dilution for $1 \mathrm{~h}$ at $25^{\circ} \mathrm{C}$. Bound secondary antibody was detected using an enhanced chemiluminescence system (Pierce; Thermo Fisher Scientific, Inc.).

Statistical analysis. All data were analyzed with the SPSS software version 16.0 (SPSS, Inc., Chicago, IL, USA). All data are presented as the mean \pm standard deviation from at least three different experiments. Statistical significance was compared between various treatment groups and controls using one-way analysis of variance followed by Dunnett's test. $\mathrm{P}<0.05$ was considered to indicate a statistically significant difference.

\section{Results}

Resveratrol inhibits T24 cell adhesion to fibronectin. Since the adhesion of tumor cells to the ECM is considered an important step in the invasive process of metastatic tumors, the effects of resveratrol on cell adhesion were examined. The results revealed that incubation of T24 cells with $0-100 \mu \mathrm{M}$ resveratrol significantly inhibited cell adhesion to the fibronectin-coated plates in a concentration-dependent manner (Fig. 1).

Resveratrol inhibits T24 cell migration. Cell migration was measured using a wound-healing assay, which is commonly used to determine the effects of pro- and anti-migratory agents on cultured cells. T2 4 cells were treated with $0-50 \mu \mathrm{M}$ resveratrol, in order to detect whether the migratory potential of T24 cells was decreased. As shown in Fig. 2, the wound-healing assay revealed that cells treated with $10-50 \mu \mathrm{M}$ resveratrol exhibited reduced wound closure. These results indicated that treatment with resveratrol may induce significant suppression 


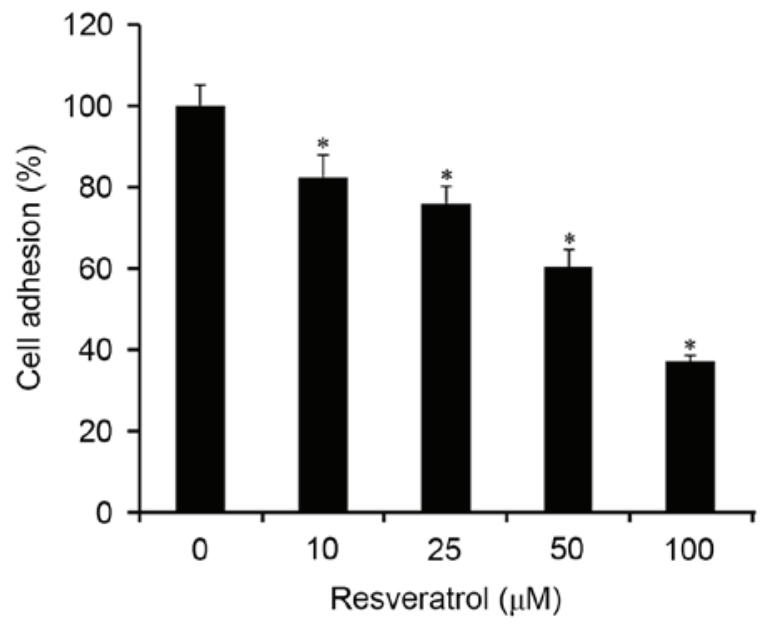

Figure 1. Resveratrol inhibits T24 cell adhesion to fibronectin. Treatment of T24 cancer cells with resveratrol $(0-100 \mu \mathrm{M})$ resulted in the suppression of cell adhesion to fibronectin. The proportion of adherent cells was counted as a percentage of the control. ${ }^{*} \mathrm{P}<0.05$ vs. $0 \mu \mathrm{M}$.

\section{$\mathbf{A}$}
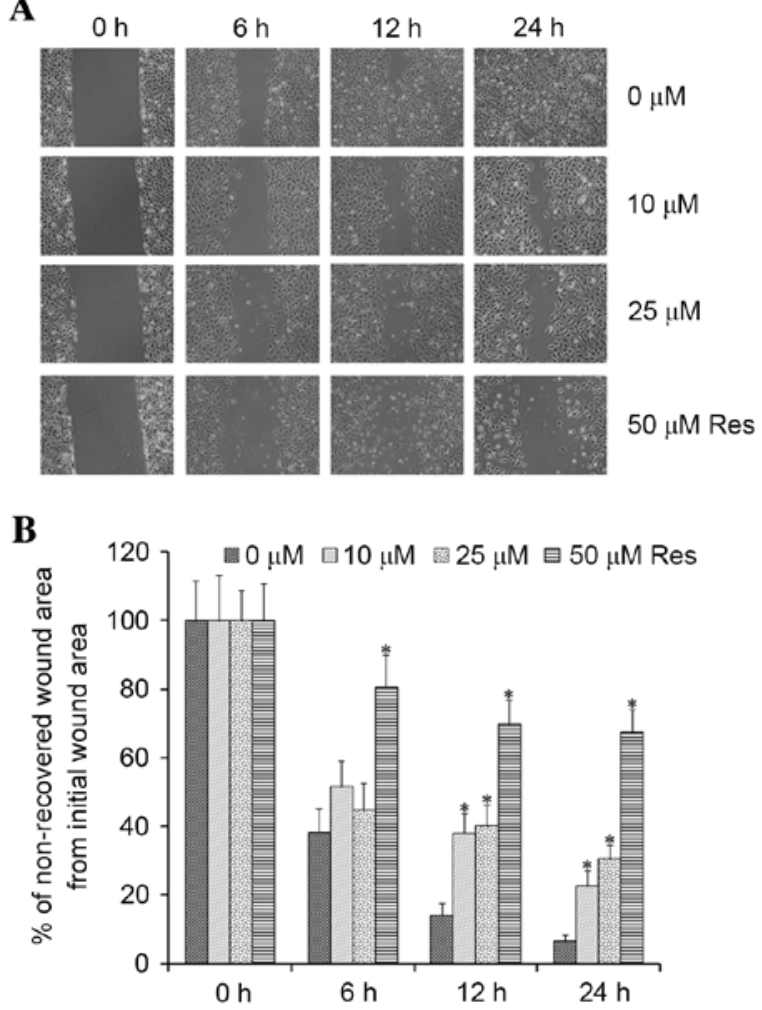

Figure 2. Resveratrol suppresses cell motility in a wound-healing assay. T24 cells were treated with $0-50 \mu \mathrm{M}$ resveratrol and wound-healing assays were performed after $0,6,12$ and $24 \mathrm{~h}$ of migration. (A) Representative images presenting the inhibitory effects of resveratrol on cell migration after the indicated durations. Magnification, x100.(B) Graph indicating the percentage of non-recovered wound area from the initial wound area after the indicated durations. ${ }^{*} \mathrm{P}<0.05$ vs. $0 \mu \mathrm{M}$ at the corresponding time-point. Res, resveratrol.

of the migratory capability of T24 cells in a dose-dependent manner.

Resveratrol inhibits T24 cell invasion. The present study further evaluated the anti-metastatic activity of resveratrol using a Transwell assay. The ability of T24 cells to permeate
A

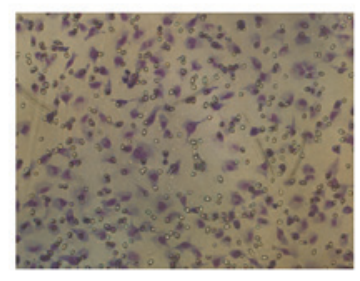

Control

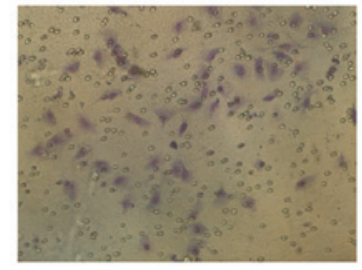

$25 \mu \mathrm{M}$ Res

B

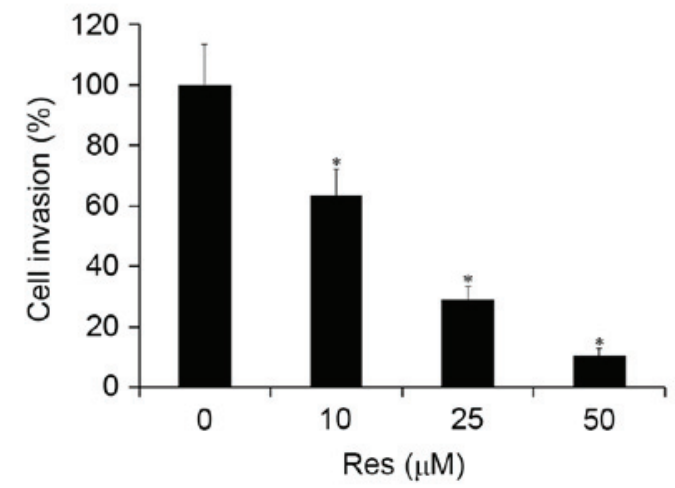

Figure 3. Resveratrol inhibits T24 cell invasion. The cells were treated with 0-50 $\mu \mathrm{M}$ resveratrol and invasion through Matrigel-coated Transwell membranes was measured. After $24 \mathrm{~h}$, the cells were fixed, stained and counted. (A) Representative images of the invasive cells that attached to the lower surface of the filter, following incubation with various concentrations of resveratrol. Magnification, $\mathrm{x} 400$. (B) Graph indicating the proportion of invasive cells, presented as a percentage of the control. ${ }^{*} \mathrm{P}<0.05$ vs. $0 \mu \mathrm{M}$. Res, resveratrol.

through a reconstituted basement membrane barrier (Matrigel) was determined following treatment with or without resveratrol. Similar to the migration assay, resveratrol inhibited the invasion of T24 cells in a dose-dependent manner. When T24 cells were grown on Matrigel, a significant reduction in the number of invasive cells was detected when the cells were treated with $10-50 \mu \mathrm{M}$ resveratrol for $24 \mathrm{~h}$, as compared with the control group, with the levels of invasion being reduced to 63.4 and $10.3 \%$ of the control levels at 10 and $50 \mu \mathrm{M}$ resveratrol, respectively (Fig. 3).

Resveratrol downregulates the protein expression levels of MMP-2 and MMP-9. It is well known that MMP-2 and MMP-9 serve important roles in the invasion of cancer cells. The present study aimed to determine whether resveratrol was able to inhibit the secretion of MMP-2 and MMP-9 in T24 cells. As presented in Fig. 4, MMP-2 and MMP-9 expression was suppressed by resveratrol treatment in T24 cells, in a dose-dependent manner.

Resveratrol downregulates the phosphorylation levels of $J N K 1 / 2$ and ERK1/2. To further investigate the mechanisms 


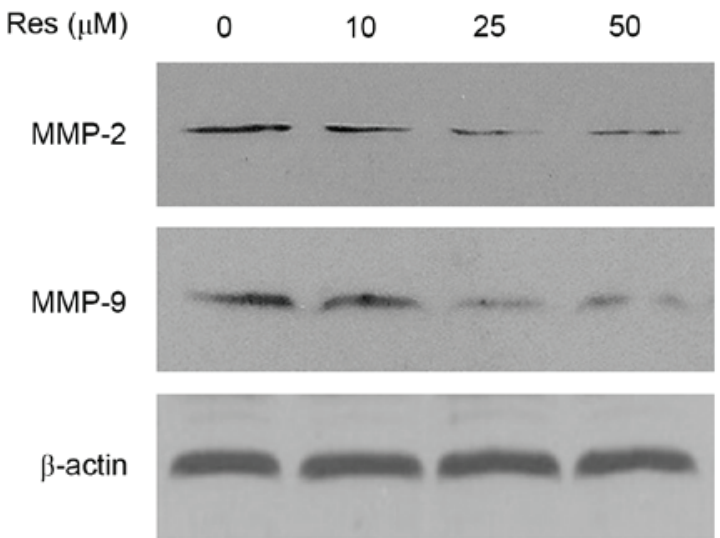

Figure 4. Resveratrol reduces the expression of MMP-2 and MMP-9 at the protein level. Protein expression in cells treated with the indicated concentrations of resveratrol $(0-50 \mu \mathrm{M})$ for $24 \mathrm{~h}$, as determined by western blotting. Resveratrol downregulated the expression of MMP-2 and MMP-9. Res, resveratrol; MMP, matrix metalloproteinase.

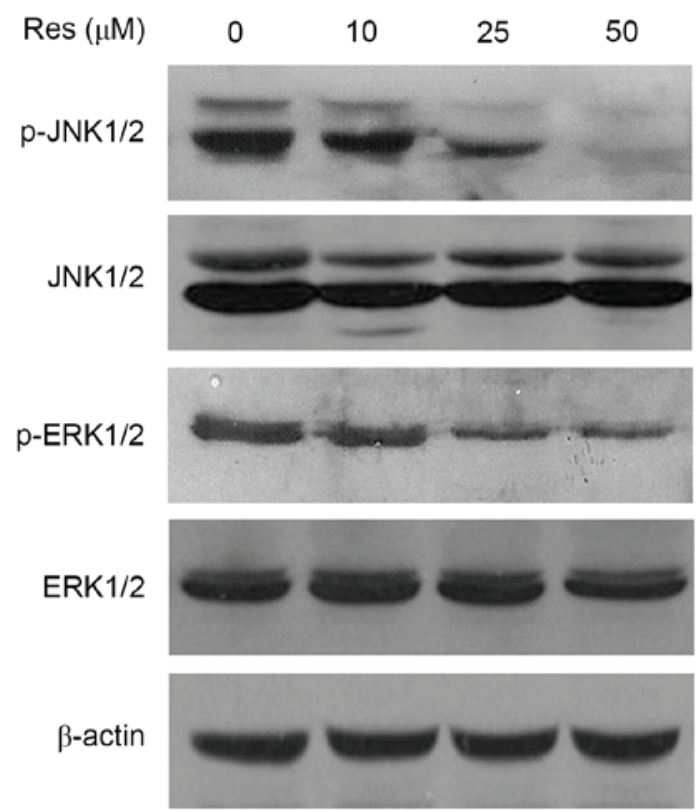

Figure 5. Resveratrol inhibits activation of JNK1/2 and ERK1/2. Cells were treated with various concentrations of resveratrol (0-50 $\mu \mathrm{M})$ for $24 \mathrm{~h}$. Resveratrol reduces the phosphorylation levels of JNK1/2 and ERK1/2, as determined by western blotting. Res, resveratrol; p-, phosphorylated-; JNK1/2, c-Jun N-terminal kinase 1/2; ERK1/2, extracellular signal-regulated protein kinase $1 / 2$.

by which resveratrol inhibits cellular adhesion, migration and invasion, the present study examined alterations in the JNK1/2 and ERK1/2 pathways, which are closely associated with cancer cell metastasis. The results of western blotting indicated that resveratrol inhibited the phosphorylation of JNK $1 / 2$ and ERK1/2 in T24 bladder cancer cells in a dose-dependent manner. However, resveratrol had no marked effect on the total protein levels of JNK1/2 and ERK1/2 (Fig. 5).

\section{Discussion}

Metastasis is the most fatal characteristic of bladder cancer, and is a multistep process that is dependent on cellular activities, including migration and invasion of cancer cells (18). In the present study, adhesion, wound healing and invasion assays demonstrated that resveratrol was able to effectively inhibit the migration and invasion of T24 cells in vitro. The present study is the first, to the best of our knowledge, to present these findings.

MMPs serve an important role in tumor angiogenesis, metastasis and stimulation of growth factor release from the ECM. MMP-2 and MMP-9 are major ECM components of the basement membrane, and have been suggested to be important for the invasive and metastatic potential of various malignancies, including bladder cancer. Furthermore, the upregulation of these MMPS has been associated with the poor prognosis of patients with bladder cancer (19-21). Therefore, the inhibition of MMP expression may be considered an early target for the prevention of cancer metastasis $(22,23)$. The present study demonstrated that resveratrol decreased the secretion of MMP-2 and MMP-9 protein in a dose-dependent manner in T24 cells. The results indicated that resveratrol may act as an important regulator of ECM breakdown during tumor invasion and metastasis, as a result of its ability to regulate MMP production.

The mitogen-activated protein kinase (MAPK) pathways, which are comprised of at least three subfamilies: ERK1/2, JNK and p38, are frequently activated in the process of tumor development, and the activation status of MAPK pathways is essential for successful metastasis (24). Numerous studies have demonstrated that JNK1/2 and ERK1/2 transcriptionally regulate the expression of MMP-2 and MMP-9, which results in regulation of cell migration and invasion (25-27). In human bladder cancer cells, upregulation of the MAPK pathways may result in migration and regulation of the expression levels of MMPs (28). Furthermore, it has been reported that decreased phosphorylation of ERK1/2 and JNK may be involved in regulation of bladder cancer cell migration (29). Therefore, interrupting MMP expression and MAPK pathway activation may be a potential approach used in anti-metastatic therapy. Consistent with this hypothesis, the present study demonstrated that phosphorylation of JNK1/2 and ERK1/2 was inhibited, which may be the cause of the downregulation of MMP-2 and MMP-9.

In conclusion, these findings suggested that resveratrol exhibits numerous anti-metastatic activities in T24 bladder cancer cells. The possible mechanism underlying resveratrol-induced inhibition of T24 cell migration and invasion may be suppression of MAPK activation (JNK and ERK), thus resulting in the inhibition of MMP-2 and MMP-9. The results of the present study indicated that resveratrol may be considered a therapeutic agent in the inhibition of bladder cancer progression, and these findings provide a novel mechanistic insight into the potential effects of resveratrol on the suppression of bladder cancer invasion and metastasis.

\section{Acknowledgements}

The present study was supported by grants from the National Natural Science Foundation of China (grant no. 81201767) and the Joint Special Funds for the Department of Science and Technology of Yunnan Province-Kunming Medical University (grant no. 2013FZ277). 


\section{References}

1. Siegel RL, Miller KD and Jemal A: Cancer statistics, 2015. CA Cancer J Clin 65: 5-29, 2015.

2. Kirkali Z, Chan T, Manoharan M, Algaba F, Busch C, Cheng L, Kiemeney L, Kriegmair M, Montironi R, Murphy WM, et al: Bladder cancer: Epidemiology, staging, and grading and diagnosis. Urology 66 (Suppl 6): S4-S34, 2005.

3. Khan N, Afaq F, Saleem M, Ahmad N and Mukhtar H: Targeting multiple signaling pathways by green tea polyphenol (-)-epigallocatechin-3-gallate. Cancer Res 66: 2500-2505, 2006.

4. Hosono T, Fukao T, Ogihara J, Ito Y, Shiba H, Seki T and Ariga T: Diallyl trisulfide suppresses the proliferation and induces apoptosis of human colon cancer cells through oxidative modification of beta-tubulin. J Biol Chem 280: 41487-41493, 2005.

5. Zhu Y, Wu J, Li S, Wang X, Liang Z, Xu X, Xu X, Hu Z, Lin Y, Chen $\mathrm{H}$, et al: Apigenin inhibits migration and invasion via modulation of epithelial mesenchymal transition in prostate cancer. Mol Med Rep 11: 1004-1008, 2015.

6. Wang Q, Xu J, Rottinghaus GE, Simonyi A, Lubahn D, Sun GY and Sun AY: Resveratrol protects against global cerebral ischemic injury in gerbils. Brain Res 958: 439-447, 2002.

7. Russo A,Palumbo M, Aliano C,Lempereur L, Scoto G and Renis M: Red wine micronutrients as protective agents in Alzheimer-like induced insult. Life Sci 72: 2369-2379, 2003.

8. Jang M, Cai L, Udeani GO, Slowing KV, Thomas CF, Beecher CW, Fong HH, Farnsworth NR, Kinghorn AD, Mehta RG, et al: Cancer chemopreventive activity of resveratrol, a natural product derived from grapes. Science 275: 218-220, 1997.

9. Clément MV, Hirpara JL, Chawdhury SH and Pervaiz S: Chemopreventive agent resveratrol, a natural product derived from grapes, triggers CD95 signaling-dependent apoptosis in human tumor cells. Blood 92: 996-1002, 1998.

10. Aziz MH, Nihal M, Fu VX, Jarrard DF and Ahmad N: Resveratrol-caused apoptosis of human prostate carcinoma LNCaP cells is mediated via modulation of phosphatidylinositol 3'-kinase/ Akt pathway and Bcl-2 family proteins. Mol Cancer Ther 5: $1335-1341,2006$.

11. Tang HY, Shih A, Cao HJ, Davis FB, Davis PJ and Lin HY: Resveratrol-induced cyclooxygenase- 2 facilitates p53-dependent apoptosis in human breast cancer cells. Mol Cancer Ther 5: 2034-2042, 2006

12. Tessitore L, Davit A, Sarotto I and Caderni G: Resveratrol depresses the growth of colorectal aberrant crypt foci by affecting bax and p21(CIP) expression. Carcinogenesis 21: 1619-1622, 2000.

13. Sun Y, Wang H, Liu M, Lin F and Hua J: Resveratrol abrogates the effects of hypoxia on cell proliferation, invasion and EMT in osteosarcoma cells through downregulation of the HIF-1 $\alpha$ protein Mol Med Rep 11: 1975-1981, 2015.

14. Gao Q, Yuan Y, Gan HZ and Peng Q: Resveratrol inhibits the hedgehog signaling pathway and epithelial-mesenchymal transition and suppresses gastric cancer invasion and metastasis. Oncol Lett 9: 2381-2387, 2015 .

15. Jiao Y, Li H, Liu Y, Guo A, Xu X, Qu X, Wang S, Zhao J, Li Y and Cao Y: Resveratrol inhibits the invasion of glioblastoma-initiating cells via down-regulation of the PI3K/Akt/NF- $\mathrm{KB}$ signaling pathway. Nutrients 7: 4383-4402, 2015.
16. Sternlicht MD and Werb Z: How matrix metalloproteinases regulate cell behavior. Annu Rev Cell Dev Biol 17: 463-516, 2001.

17. Mook OR, Frederiks WM and Van Noorden CJ: The role of gelatinases in colorectal cancer progression and metastasis. Biochim Biophys Acta 1705: 69-89, 2004.

18. Steeg PS: Tumor metastasis: Mechanistic insights and clinical challenges. Nat Med 12: 895-904, 2006.

19. Zhang L, Shi J, Feng J, Klocker H, Lee C and Zhang J: Type IV collagenase (matrix metalloproteinase-2 and -9) in prostate cancer. Prostate Cancer Prostatic Dis 7: 327-332, 2004.

20. Kader AK, Liu J, Shao L, Dinney CP, Lin J, Wang Y, Gu J, Grossman $\mathrm{HB}$ and $\mathrm{Wu} \mathrm{X}$ : Matrix metalloproteinase polymorphisms are associated with bladder cancer invasiveness. Clin Cancer Res 13: 2614-2620, 2007.

21. Qin J, Wang Y, Bai Y, Yang K, Mao Q, Lin Y, Kong D, Zheng X and Xie L: Epigallocatechin-3-gallate inhibits bladder cancer cell invasion via suppression of $\mathrm{NF}-\kappa \mathrm{B}$-mediated matrix metalloproteinase-9 expression. Mol Med Rep 6: 1040-1044, 2012.

22. Waas ET, Wobbes T, Lomme RM, DeGroot J, Ruers T and Hendriks T: Matrix metalloproteinase 2 and 9 activity in patients with colorectal cancer liver metastasis. Br J Surg 90: 1556-1564, 2003

23. Guruvayoorappan C and Kuttan G: Amentoflavone inhibits experimental tumor metastasis through a regulatory mechanism involving MMP-2, MMP-9, prolyl hydroxylase, lysyl oxidase, VEGF, ERK-1, ERK-2, STAT-1, NM23 and cytokines in lung tissues of C57BL/6 mice. Immunopharmacol Immunotoxicol 30: 711-727, 2008.

24. Reddy KB, Nabha SM and Atanaskova N: Role of MAP kinase in tumor progression and invasion. Cancer Metastas Rev 22: 395-403, 2003

25. Crowe DL, Tsang KJ and Shemirani B: Jun N-terminal kinase 1 mediates transcriptional induction of matrix metalloproteinase 9 expression. Neoplasia 3: 27-32, 2001.

26. Moon SK, Kim HM, Lee YC and Kim CH: Disialoganglioside (GD3) synthase gene expression suppresses vascular smooth muscle cell responses via the inhibition of ERK1/2 phosphorylation, cell cycle progression, and matrix metalloproteinase-9 expression. J Biol Chem 279: 33063-33070, 2004.

27. Wang BW, Chang H, Lin S, Kuan P and Shyu KG: Induction of matrix metalloproteinases-14 and -2 by cyclical mechanical stretch is mediated by tumor necrosis factor-alpha in cultured human umbilical vein endothelial cells. Cardiovasc Res 59: 460-469, 2003.

28. Lee SJ, Cho SC, Lee EJ, Kim S, Lee SB, Lim JH, Choi YH, Kim WJ and Moon SK: Interleukin-20 promotes migration of bladder cancer cells through extracellular signal-regulated kinase (ERK)-mediated MMP-9 protein expression leading to nuclear factor $(\mathrm{NF}-\kappa \mathrm{B})$ activation by inducing the up-regulation of p21(WAF1) protein expression. J Biol Chem 288: 5539-5552, 2013

29. Gong Y, Qiu W, Ning X, Yang X, Liu L, Wang Z, Lin J, Li X and Guo Y: CCDC34 is up-regulated in bladder cancer and regulates bladder cancer cell proliferation, apoptosis and migration. Oncotarget 6: 25856-25867, 2015. 